\title{
㪌 New Disease Reports \\ First report of Xylaria sp. causing tuber rot on glory lily in India
}

\author{
S. Kousalya ${ }^{1}$, A. Kamalakannan ${ }^{1}$, A. Chowdappa ${ }^{1}$, C. Gopalakrishnan ${ }^{1}$, K. Rajamani ${ }^{2}$ and A. Venkatesh $^{1}$ \\ ${ }^{1}$ Department of Plant Pathology, Center for Plant Protection studies, Tamil Nadu Agricultural University, Coimbatore - \\ 641003, India; ${ }^{2}$ Department of Medicinal and Aromatic Crops, Tamil Nadu Agricultural University, Coimbatore - 641003, \\ India
}

*E-mail: kousyagri@gmail.com

Received: 21 Mar 2019. Published: 08 Jun 2019. Keywords: Gloriosa superba, fungal plant disease

Glory lily (Gloriosa superba, family Colchicaceae) is a medicinal plant grown commercially in India. The tubers and seeds are rich in colchicines, isoperlolyrine and tropolane alkaloids which have anti-gout, antiinflammatory and anti-tumour activity (Pandey et al., 2008).

In July 2015, a survey was conducted in the major growing areas of Tamil Nadu state. A tuber rot disease was observed at the flowering stage (90 days after planting) in all surveyed areas, that is the Dindigul, Erode, Karur, Salem and Tiruppur districts of the state. Initial disease symptoms were yellowing and drying of leaves (Fig. 1) and white mycelial growth on the collar region of stem and roots (Fig. 2), which led to rotting of tubers (Fig. 3 ) and a severe loss in seed yield. Infected tubers were surface sterilised using $0.1 \%$ mercuric chloride solution. A fungus was consistently isolated from diseased tubers plated on potato dextrose agar medium and incubated at $25 \pm 2^{\circ} \mathrm{C}$ (Fig. 4). The fungal colony was initially creamy white, later turning greyish black in colour. Single-celled cylindrical hyaline conidia measuring 3-4 $\mu \mathrm{m} \times 1-2 \mu \mathrm{m}$ were produced at the tips of conidiophores. Based on the morphological characters, the fungus was identified as Xylaria sp. and the identification was confirmed by the Indian Type Culture Collection, Indian Agricultural Research Institute, New Delhi (reference no. 868/88).

Molecular identification was done using fungal-specific primers (unpublished commercial primers) for amplification of ITS 1 and ITS 2 regions of nRNA (forward, 5'-TCMGTAGGTGAPCCWBCGS-3' and reverse, 5'-TCCTNCGYTKATKGUTADGH-3'), using an initial denaturation step at $94^{\circ} \mathrm{C}$ for 5 minutes, 35 cycles of 30 seconds at $94^{\circ} \mathrm{C}$, 30 seconds at $52^{\circ} \mathrm{C}$ and 45 seconds at $72^{\circ} \mathrm{C}$, and final extension at $72^{\circ} \mathrm{C}$ for 7 minutes (Lee et al., 2000). The 650 bp PCR product was sequenced (GenBank Accession No. KX419439) and BLAST analysis showed 99\% identity with a Xylaria sp. isolated from mushroom in India (KR155088). A phylogenetic tree was constructed and the fungus was shown to be an undescribed Xylaria sp., closely related to isolate R006 from India (KC405623.1).

To confirm pathogenicity, sand and ground maize seeds were mixed (19:1, $\mathrm{v} / \mathrm{v}$, respectively), moistened with water and sterilised by autoclaving. The fungus was inoculated into the medium and incubated for 28 days at 28 $\pm 2^{\circ} \mathrm{C}$ (Riker \& Riker, 1936). Earthen pots $(25 \mathrm{~cm}$ diameter) were filled with $5 \mathrm{~kg}$ potting medium (equal volumes of red soil, sand and farmyard manure). The medium was sterilised by autoclaving and inoculated with $5 \mathrm{~g}$ Xylaria inoculum. Healthy tubers of G. superba were planted in pots, maintained in a glasshouse with uniform watering, and assessed after 90 days. The inoculated plants developed symptoms similar to those observed in the field, including yellowing of leaves and rotting of tubers. Koch's postulates were fulfilled by re-isolation of the fungus from the infected tubers and molecular identification of Xylaria sp. by sequencing. Control plants did not show any symptoms.

A tuber rot disease of glory lily caused by Macrophomina phaseolina wasobserved by Alice \& Sundravadhana (2012). However, to the best of our knowledge, this is the first report of Xylaria sp. infecting glory lily and causing tuber rot disease, either in India or worldwide.

\section{Acknowledgements}

The first author acknowledges indebtedness and heartfelt thanks to Dr. A. Raja Rajan Dean, RKMVU for his valuable suggestions and strengthening my self-confidence at all times.

\section{References}

Alice D, Sundravadana S, 2012. Effects of biocontrol agents and plant products Macrophomina phaseolina and colchicine content in Gloriosa superba. Plant Protection Science 48, 110-115.

http://dx.doi.org/10.17221/18/2011-PPS

Lee JS, Ko KS, Jung HS, 2000. Phylogenetic analysis of Xylaria based on nuclear ribosomal ITS1-5.8S-ITS2 sequences. FEMS Microbiology Letters 187, 89-93. http://dx.doi.org/10.1016/S0378-1097(00)00181-6

Pandey AK, Shukla PK, 2008. Role of medicinal plants in health care and rural economy in the tribals of Satpura plateau region of central India. Indian Forester 134, 1438-1446.

Riker AJ, Riker RS, 1936. Introduction to research on plant disease. St. Louis, USA: John Swift Co.

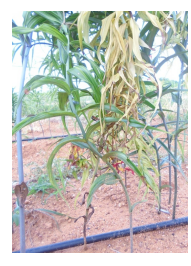

Figure 1

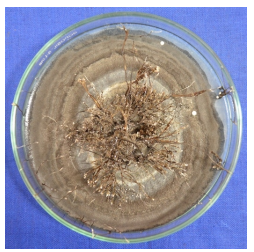

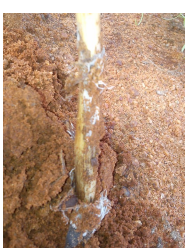

Figure 2

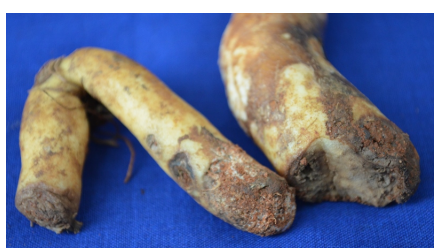

Figure 3

Figure 4

To cite this report: Kousalya S, Kamalakannan A, Chowdappa A, Gopalakrishnan C, Rajamani K, Venkatesh A, 2019. First report of Xylaria sp. causing tuber rot on glory lily in India. New Disease Reports 39, 21. http://dx.doi.org/10.5197/j.2044-0588.2019.039.021 (c) 2019 The Authors This report was published on-line at www.ndrs.org.uk where high quality versions of the figures can be found. 